\title{
Mergers, Spin-offs, and Employee Incentives
}

\author{
Paolo Fulghieri \\ Merih Sevilir \\ University of North Carolina University of North Carolina
}

\begin{abstract}
This paper studies mergers between competing firms and shows that while such mergers reduce the level of product market competition, they may have an adverse effect on employee incentives. In industries where value creation depends on innovation and development of new products, mergers are likely to be inefficient even though they increase the market power of the post-merger firm. In such industries, a stand-alone structure where independent firms compete both in the product market and in the market for employee human capital leads to a greater profitability. Furthermore, our analysis shows that multidivisional firms can improve employee incentives and increase firm value by reducing firm size through a spin-off transaction although doing so reduces the benefits of operating an internal capital market within the firm.
\end{abstract}

To be presented at the AFA 2010 meetings. We thank seminar participants at ESMT, Oxford University and University of Virginia for useful comments. All errors are our own. 


\section{Introduction}

This paper studies the effect of mergers on employee incentives, and develops a theory of firm organization structure as a function of industry characteristics such as the size of the industry and the failure probability associated with developing new products in the industry. We show that in early stage industries with greater human capital intensity, mergers between competing firms can be inefficient since they may weaken employee incentives. Hence, our paper provides an explanation for why many mergers fail to create value even though they reduce the level of competition in the product market. In addition, our analysis suggests that a multidivisional firm can improve employee incentives and create value by reducing firm size through a spin-off transaction.

In our model, we consider two firms operating in the same product market where firm value is created by developing innovations generated by employees. Innovation arises as an outcome of costly effort exerted by employees. The firms can choose between two types of organization structure. The first is a stand-alone structure where the two firms operate independently in the same product market. The second is a merger where the two firms merge into a single firm. The stand-alone structure and the merger are different in terms of their effect on product market competition and competition for employee human capital. In the stand-alone structure the two firms compete with each other in the final goods market. In addition, the presence of two separate firms in the same product market implies that employees can move from one firm to another, implying that the firms also compete for employee human capital. The merger combines the two firms into a single firm, and reduces competition in the product market. At the same time, the merger also reduces competition for employee human capital by decreasing the number of stand-alone firms in the industry.

In our model, firm expected profits critically depend on the choice of organization structure. In the stand-alone structure, greater competition in the product market is costly for firms since it implies a lower ex post payoff from employee innovations. Further, the stand-alone structure also leads to greater competition for employee human capital and increases employee rents. Although 
higher employee rents imply lower firm payoffs from employee innovations, they may have a positive effect on ex ante firm profits by improving employee effort. This is because in the absence of complete contracts, employees face a hold-up problem where they may obtain too low rents from ex post bargaining with their firm, especially if their bargaining power is low. The stand-alone structure mitigates employees' concern about being held-up by their firm because the presence of multiple firms in the same product market provides the employees with the ability to move from one firm to another. This, in turn, increases employee rents from obtaining an innovation, with a positive effect on their incentives.

The merger, in contrast, reduces product market competition between the two firms, with a positive effect on firm ex post payoff from employee innovations. In addition, the merger provides the co-insurance benefit typically associated with internal capital markets (as in Stein, 1997) of having two employees, rather than only one, exerting innovation effort, which can increase the probability of obtaining an innovation. However, the merger has two adverse effects on employee incentives: First, it decreases the number of firms in the same product market, and reduces the extent of competition for human capital. Second, the presence of two employees allows the postmerger firm to extract greater rents from the employees. Both effects lead to weaker employee incentives to exert innovation effort. From the firms' perspective, while the merger always leads to greater ex post payoff from employee innovations, it can still reduce ex ante firm expected profits if its negative effects on employee incentives are sufficiently large. ${ }^{1}$

We show that the two firms, under certain conditions, do not find it desirable to merge even if doing so provides the post-merger firm with the co-insurance benefit and a greater market power. This happens precisely because the merger can have a negative effect on employee incentives to innovate. Hence, our paper offers an explanation for why many mergers fail to create value, and why mergers might be bad for innovation and development of new products. This result is particularly relevant given the findings in Hoberg and Phillips (2009) that mergers are motivated by the desire to introduce and develop new products in order to enter new product markets.

\footnotetext{
${ }^{1}$ See Rotemberg and Saloner (1994) for a similar effect of having two employees on ex ante incentives.
} 
A novel result from our analysis is that the positive effect of the stand-alone structure on employee incentives is most valuable especially in early stage industries with smaller size and high failure probability. Improving employee incentives by facilitating employee mobility across competing firms turns out to be very desirable in such industries since, in the absence of employee mobility, a small market size and high risk inherent in such industries fail to provide sufficient incentives to innovate. In addition, the desirability of the merger in terms of reducing the level of product market competition is smaller in newly emerging industries with little horizontal differentiation. Hence, an interesting implication from our model is that the stand-alone structure plays a positive role on innovation output in early stage industries with new emerging technologies, whereas in more mature industries with greater market size and lower failure risk, mergers have a positive effect on innovation output.

Our results regarding the inefficiency of mergers also imply that a multidivisional firm will benefit from reducing firm size by undertaking a spin-off transaction. The benefit of a spin-off transaction in terms of improving employee incentives can be sufficiently large that the firm finds it optimal to break itself up into two independent firms even though this increases competition in the product market, employee rents and eliminates the co-insurance advantage of operating an internal capital market.

We also study firm investment incentives for innovation, and show that a market structure where stand-alone firms compete can be more innovation-friendly than a monopoly structure where a larger firm does not face any competition. This is because employee incentives in the larger firm can be so weak that the firm does not have sufficient incentives to invest towards innovation. This result arises in spite of the fact that the monopolistic firm is larger, pays lower employee rents, faces no competition, and enjoys economies of scale, relative to a stand-alone firm. This finding also implies that firm incentives to invest in innovation will increase after a spin-off transaction.

Our paper is related to the literature on internal capital markets and the theory of the 
firm. ${ }^{2}$ In our model the merger setting exhibits features similar to the internal capital markets in that the post-merger firm has two employees, allowing the firm to create value as long as at least one of them is successful. This feature is similar to winner picking advantage of internal capital markets identified in Stein (1997). In addition, in our model the firm gains a bargaining advantage when it has two "winners" by playing each winner against the other. Interestingly, this ex post bargaining advantage may not be always desirable for the firm since it leads to an ex ante inefficiency by weakening employee incentives. In addition, the merger further increases the rent extraction ability of the firm by reducing the number of stand-alone firms to which employees can transfer their human capital. This second effect also has a negative effect on employee incentives to innovate. In other related work, Mathews and Robinson (2006) examine how a firm chooses its optimal organizational design as an interaction between product markets and capital markets. They compare a stand-alone firm and an integrated firm in terms of their effect on entry deterrence and on predatory capital raising, and show that the integrated firm's greater flexibility in resource allocation can deter entry from stand-alone firms when product markets are uncertain.

Our paper is also related to the literature examining the interaction between location choice of firms and incentives to undertake relation specific investment. Rotemberg and Saloner (2000) show that the equilibrium locations of firms and their input suppliers are determined interdependently in a way to mitigate the hold-up problem between the input suppliers and buyers of inputs. Similarly, Matouschek and Robert-Nicoud (2005) and Almazan, De Motta and Titman (2007) study the link between firm location and employee incentives to invest in human capital. Matouschek and Robert-Nicoud (2005) show that the location decision of firms depends on whether the firm or the employee invests in human capital, and whether human capital investment is industry-specific or firm-specific. In Almazan et al. (2007), geographical proximity promotes the development of a competitive labor market, and firms prefer to cluster when employees pay

\footnotetext{
${ }^{2}$ See, among others, Gertner, Scharfstein and Stein (1994), Scharfstein and Stein (2000), Fulghieri and Hodrick (2006). For a review of this literature, see Stein (2003).
} 
for their own training, while they locate apart from industry clusters when firms pay for their employees' human capital development. ${ }^{3}$

Although several papers study the existence and the benefits of industry clusters, an important and unexplored question is to examine the incentives of firms located within the same industry clusters to merge. Our paper shows that the merger decision depends on its effect on the extent of the hold-up problem between the post-merger firm and the employees as well as its effect on the level of competition in the product market. We find that firms will be more willing to cluster, pay greater employee rents and bear greater competition in the product market especially in early stage industries, with smaller market size and greater failure probability of developing new products. As the industry matures, becomes larger, and less risky, firms within the cluster will find it more desirable to merge to reduce product market competition.

Our paper is related to the literature studying the relation between product market competition and innovation in the context of an agency problem between firms and managers. ${ }^{4}$ In our model, competition plays a role in mitigating the extent of the hold-up problem between the firms and the employees. When the benefit of competition in improving employee incentives is sufficiently large, the firms choose to operate as stand-alone firms. Otherwise, they merge and reduce competition in the product market as well as competition for employee human capital.

Our paper suggests that firms in similar product markets may benefit from enhancing employee mobility by adopting compatible technologies or choosing similar industry standards. This is because the creation of homogeneous industry standards could facilitate the transferability of employee human capital from one firm to another. Such practices will be particularly desirable in emerging industries with greater failure probability since improving employee incentives has the highest benefit in such industries. Similarly, our model shows why it may be detrimental for human capital intensive firms to restrict employee mobility by requiring employees to sign "no-compete" agreements which limit employee ability to work for other firms. Imposing a nocompete agreement reduces employee incentives to innovate by weakening the outside option of

\footnotetext{
${ }^{3}$ See Duranton and Puga (2004) for a review of work on agglomeration economies.

${ }^{4}$ See, among others, Hart (1983), Scharfstein (1988), and Schmidt (1997).
} 
the employee, ultimately leading to lower innovation output and firm profitability.

The paper is organized as follows. In section 2, we present the basic model, and analyze the stand-alone structure and the merger. Section 3 examines firm investment incentives for innovation as a function of firm organizational structure. Section 4 discussed the implications of our model in the context of spin-off transactions. Section 5 analyzes firm incentives to take ex ante actions to improve employee mobility. Section 6 presents the empirical predictions of our model, and Section 7 concludes. All proofs are in the Appendix.

\section{The Model}

We consider an economy where firms operate in imperfectly competitive markets, both in the final goods market and the labor market. For analytical tractability we restrict our attention to two firms and two employees. All agents are risk-neutral and there is no discounting. We assume that at the beginning of the game each firm is already matched with one of the two employees. We also assume that the employees have limited wealth and rule out ex ante monetary transfers between the firms and the employees. The two firms are human capital intensive in the sense that they create value by developing employee-generated innovations. An innovation involves two stages of a project. The first stage of the project is performed by the employee and, if successful, generates an innovation. ${ }^{5}$ The second stage involves the development of the innovation and is performed by the firm with the collaboration of the employee. We assume that the active participation of the employee who initially generated the innovation is necessary in the second stage for its development into a final product. ${ }^{6}$ Although our initial model assumes that the only necessary

\footnotetext{
${ }^{5}$ Innovation can be broadly interpreted as any new idea or new product which improves firm profitability.

${ }^{6}$ This assumption implies that if an employee with a successful innovation leaves his firm at the end of the first stage, the firm cannot implement the innovation without the original employee. Similarly, if the employee leaves the firm, he cannot implement the innovation by himself but he must join another firm with the resources and capabilities necessary to implement the innovation. We also assume that the employee needs the firm's resources during both stages of the production process, which implies that he can generate an innovation only if he has joined a firm at the beginning of the game.
} 
input for generating an innovation is employee effort, in Section 3 we relax this assumption and study firm innovation incentives in a more realistic setting where employees are able to innovate only if their firm makes an investment before they exert effort.

The success probability in the first stage of the project depends on effort exerted by the employee, denoted by $e_{i}, i=1,2$. If an employee fails to obtain an innovation, the project is worthless. Employee effort determines the success probability $p$ of the project such that $p_{i}\left(e_{i}\right)=$ $e_{i} \in[0,1]$. Exerting effort is costly: we assume that effort costs are convex and given by $\frac{k}{2} e_{i}^{2}$ where $k$ measures the unit cost of exerting such effort. We interpret employee effort broadly as representing the costly investment made by the employee to acquire the knowledge and human capital necessary for the success of the project.

In our model, employee incentives to exert effort depend on the organizational structure that their firms choose. The firms either choose to operate stand-alone, or choose to merge into one single firm. If they choose the stand-alone structure, they operate in the same product market as separate firms, with each firm having one employee. In this case, it is possible for the employees to transfer (albeit imperfectly) their innovation and human capital from one firm to the other. This assumption captures the notion that the presence of other firms in the same product market enables employees to develop human capital that can be valued outside their current firm. Hence, the stand-alone structure not only leads to competition in the product market, but also creates competition for scarce employee human capital, with a positive effect on employee incentives.

If the two firms choose to merge, the post-merger firm operates as a monopolist in the product market with two employees. This implies that employee innovations can only be developed within the post-merger firm, since there is no rival firm in the product market to which employees can transfer their innovation. Thus, the merger eliminates competition in the product market as well as competition for employee human capital.

Note that our assumption that we have only two firms in the product market implies that if they merge, the new firm will be a monopolist in the product market. In addition, since there will not be any other firms in the product market, the employees lose their ability to move from one 
firm to another. More realistically, after a merger in an industry there will be other independent firms which will compete with the newly merged firm. In addition, employees of the post-merger firm will still have the ability to move to other existing firms in the industry. Hence, the merger will not completely eliminate competition but reduce it. Our assumption that we have only two firms, and their decision to merge eliminates competition is only for analytical tractability and simplicity. All we need for our results is that the merger reduces the level of product market competition as well as competition for employee human capital.

We assume that employee effort is not observable, exposing firms to moral hazard. Following Stole and Zwiebel (1996a and 1996b), and in the spirit of Grossman and Hart (1986) and Hart and Moore (1990), we also assume that the firms and the employees cannot write binding contracts contingent on the development of successful innovations and that they can withdraw their participation from the project before the development phase. If an employee generates an innovation, the allocation of the surplus from the development of the innovation is determined (as in Stole and Zwiebel, 1996a and 1996b) at the interim date by intra-firm bargaining between the firm and the employee, before the second stage of the project is performed. ${ }^{7}$

The outcome of bargaining between the employee and the firm depends on their relative bargaining power and on each party's outside option. We assume that each firm's outside option while bargaining with its employee is limited by the fact that the firm cannot replace its current employee with a new one from the general labor market population, but it can only hire an employee from a rival firm in the same product market. This assumption captures the notion that it is impossible (or infinitely costly) for the firm to continue production by replacing the original employee with a new one from the generic (unskilled) labor market pool. This assumption is easy to justify if employees need a training in the first period to produce in the second period. ${ }^{8}$

\footnotetext{
${ }^{7}$ For a further discussion on the role of employment at will and renegotiation on surplus allocation, see Stole and Zwiebel (1996a) and (1996b).

${ }^{8}$ Relaxing this assumption and allowing the firm to hire a new employee from the labor market does not change our results as long as the value created by the firm and the new employee is lower than the value created by the original employee, due to relationship specific nature of original employee's effort.
} 
The presence of an outside option for the employee depends on whether the employee can transfer his human capital from one firm to the other. This will be possible only if the employee can move from his original firm to a rival firm in the same product market, that is, if the firms choose the stand-alone structure.

Ex post payoffs from developing employee innovations depend on the organization structure choice of the firms. If the firms operate stand-alone, then the payoff from the project depends on whether the employees of one or both firms have been successful in the first stage of their project. If both firms have been successful (that is, if employees at both firms obtain an innovation) the two firms compete in the development of the innovation. We assume that the two firms engage in Bertrand competition, which drives project payoff at each firm down to $0 .{ }^{9}$ If, instead, only one of the employees succeeds in obtaining an innovation, then the firm with the successful employee will be a monopolist in the market and the project will generate payoff $M>0 .{ }^{10}$ If the two firms merge, and if at least one of the employees is successful in obtaining an innovation, then the project payoff will be $M$. Note that, different from the stand-alone structure, if both employees at the post-merger firm succeeds, the post-merger firm will not face any competition in the product market, and project payoff will still be $M$. In the remainder of the paper, we assume $M<k$ to ensure we have interior solutions.

The game unfolds as follows. At time $t=0$, the two firms decide whether to merge or to stand-alone in the same product market. If the firms decide to merge, the post-merger firm retains both employees. At $t=1$, after observing the organizational choice decision of the firms, each employee exerts effort which determines the success probability of his project.

\footnotetext{
${ }^{9}$ We make this assumption for analytical tractability. The main results of our paper can be extended to include different forms of product market competition between the two firms.

${ }^{10}$ Note that parameter $M$ may be a function of the failure probability of developing new products. To see this, suppose that conditional on an employee generating an innovation, the success of the development phase of the innovation is given by an exogenous parameter $q$, and conditional on successful development, the payoff from the innovation is given by $m$. In such a setting, the expected payoff at the development phase of an innovation is given by $M=q m$. Hence, ex ante, the project payoff $M$ will be lower when the failure probability of developing new products is higher.
} 
At $t=2$, the outcome of the first stage of the project is known. If the first stage is successful, then each employee bargains with his firm over the division of the surplus from the development of the innovation. The share of the surplus obtained by the employee may be interpreted as the wage (or bonus) that the employee receives for his contribution necessary for the subsequent development and commercialization of the innovation. When bargaining with his firm, the employee captures fraction $\beta$ of the net joint surplus that depends on his bargaining power, with $\beta \in(0,1)$. Thus, we will refer to the parameter $\beta$ as employee "bargaining power."

The payoffs from bargaining depend on the employee outside option which, in turn, depends on whether the two firms operate stand-alone or merge. If the firms operate stand-alone, employee human capital can be redeployed at the rival firm. This possibility generates an outside option for an employee when bargaining with his own firm. Specifically, we assume that the employee can transfer his innovation to the competing firm, where it can be developed with payoff $\delta \leq M$. We interpret parameter $\delta$ as measuring the degree of transferability of employee human capital across firms. We assume initially that $\delta$ is an exogenous parameter; in Section 5 we allow firms to choose the value of $\delta$ endogenously at the time of the organizational structure decision at $t=0$. If the two firms merge into a single firm, the employees cannot transfer their innovation to any other firm since after the merger, the post-merger firm is the only firm in the product market. Thus, both the employees and the post-merger firm have zero outside options while bargaining. ${ }^{11}$ At $t=3$, the payoff is realized and the cash flow is distributed.

\subsection{The stand-alone structure}

The stand-alone structure has two important implications. The first is that it exposes the firms to competition in the product market. This is costly because, when the employees in both firms are successful, competition in the product market drives payoffs for each firm down to 0 . The second implication of the stand-alone structure is that it creates competition for employee human

\footnotetext{
${ }^{11}$ Our assumption that after the merger the employees lose their ability to move to other firms (i.e., $\delta=0$ ) is only a normalization. All we need for our results is that employee mobility measured by $\delta$ and the level of product market competition are lower in the merger scenario than in the stand-alone scenario.
} 
capital. The presence of two firms in the same product market implies that the employees can move from one firm to another, affecting their outside option in bargaining.

The outcome of bargaining between the firms and the employees, and thus the allocation of the surplus depends on whether only one, or both employees generate an innovation. If only one employee, say employee $i$, is successful in generating an innovation, he bargains with his firm over the division of the payoff $M$. Given that employee $j$ has failed, employee $i$ has the ability to transfer his innovation, which can be developed at the competing firm $j$ with payoff of $\delta .{ }^{12}$

We model the bargaining game between employee $i$ and firm $i$ as one in which the two parties make alternating offers under the threat that the bargaining process breaks down with a certain exogenous probability. If bargaining with firm $i$ breaks down, employee $i$ has the option to start a new round of bargaining with firm $j$. Thus, the payoff from bargaining with firm $j$ represents employee $i$ 's outside option when bargaining with firm $i$. One can show that, as the probability that the bargaining process breaks down tends to zero, the outcome of the subgame perfect equilibrium of the bargaining game between firm $i$ and employee $i$ is such that the employee and the firm receive the value of their outside options (the value that they can obtain in the case of a breakdown in bargaining), plus the fractions $\beta$ and $1-\beta$, respectively, of the surplus that they jointly generate net of the sum of their outside options. ${ }^{13}$

We can determine the payoffs from bargaining between firm $i$ and employee $i$ by proceeding backwards. If bargaining between employee $i$ and firm $i$ breaks down, employee $i$ has the opportunity to bargain with firm $j$. In this second bargaining game, both employee $i$ and firm $j$ have zero outside options. Hence, employee $i$ and firm $j$ will share the joint surplus $\delta$ such that the employee obtains payoff $\beta \delta$, which represents employee $i$ 's outside option while bar-

\footnotetext{
${ }^{12}$ Note that in equilibrium the employees will not transfer their innovation to the rival firm since $\delta \leq M$. It is straightforward to extend our model such that with some exogenous probability the employees may generate a higher value when their innovation is developed at the rival firm.

${ }^{13}$ Note that this division of the surplus corresponds to the Nash-bargaining solution with outside options, in which the employee's and the firm's bargaining powers are, respectively, $\beta$ and $1-\beta$. See Binmore, Rubinstein, and Wolinski (1986).
} 
gaining with firm $i$. Since employee $j$ has failed to obtain an innovation, firm $i$ has no outside option. This implies that employee $i$ 's payoff from bargaining with firm $i$ is equal to $\beta \delta+\beta(M-$ $\beta \delta)=\beta M+\beta(1-\beta) \delta$. Note that this payoff corresponds to the employee's outside option given by $\beta \delta$, plus $\beta$ proportion of the total surplus created by employee $i$ and firm $i$ net of the sum of each party's outside option, given by $\beta(M-\beta \delta-0)$. Correspondingly, firm $i$ 's payoff is given by $(1-\beta)(M-\beta \delta)$.

If both employees have been successful, the firms compete in the product market and both the firms and the employees obtain zero payoff.

In anticipation of his payoff from bargaining, employee $i$ chooses his effort level, denoted by $e_{i}^{S}$, given the effort level $e_{j}^{S}$ exerted by employee $j$, by maximizing his expected profits denoted by $\pi_{E_{i}}^{S}$ :

$$
\max _{e_{i}^{S}} \pi_{E_{i}}^{S} \equiv e_{i}^{S}\left(1-e_{j}^{S}\right)(\beta M+\beta(1-\beta) \delta)-\frac{k}{2}\left(e_{i}^{S}\right)^{2} ; i, j=1,2 ; i \neq j .
$$

Correspondingly, firm $i$ 's expected profits denoted by $\pi_{F_{i}}^{S}$, are given by

$$
\pi_{F_{i}}^{S} \equiv e_{i}^{S}\left(1-e_{j}^{S}\right)(1-\beta)(M-\beta \delta) ; i, j=1,2 ; i \neq j
$$

The first-order condition of (1) provides employee $i$ 's optimal response, given employee $j$ 's choice of effort, as follows:

$$
e_{i}^{S}\left(e_{j}^{S}\right)=\frac{\left(1-e_{j}^{S}\right)(\beta M+\beta(1-\beta) \delta)}{k}=\frac{\beta M-e_{j}^{S} \beta M+\left(1-e_{j}^{S}\right) \beta(1-\beta) \delta}{k} ; i, j=1,2 ; i \neq j .
$$

Examination of (3) reveals that the stand-alone structure has two effects on employee incentives to exert effort. The first effect, captured by the term $-e_{j}^{S} \beta M$, is negative and reflects the reduction in employee payoff due to competition in the product market. If employee $j$ at the rival firm obtains an innovation, which occurs with probability $e_{j}^{S}$, competition in the product market drives project payoff to zero, with a negative impact on employee $i$ 's effort. The second effect, captured by the term $\left(1-e_{j}^{S}\right) \beta(1-\beta) \delta$, is positive and originates from the property that the two firms compete for employee human capital. Since employee $i^{\prime} s$ innovation is valuable at his current firm as well as at the rival firm, this creates an outside option for the employee, and enables him to extract greater rents from his firm, enhancing his incentives to exert effort. 
Note that this effect arises only when the employee at the rival firm fails, which happens with probability $1-e_{j}^{S}$.

The following lemma presents the Nash-equilibrium of the effort subgame in the stand-alone structure, and the corresponding expected profits of the employees and the firms.

Lemma 1 The Nash-equilibrium of the effort subgame under the stand-alone structure is given by:

$$
e_{i}^{S *}=e_{j}^{S *}=e^{S *} \equiv \frac{\beta M+\beta(1-\beta) \delta}{k+\beta M+\beta(1-\beta) \delta} .
$$

The corresponding expected profits for the employees and the firms are given by:

$$
\begin{aligned}
\pi_{E_{i}}^{S *} & =\frac{k(\beta M+\beta(1-\beta) \delta)^{2}}{2(k+\beta M+\beta(1-\beta) \delta)^{2}} ; i=1,2, \\
\pi_{F_{i}}^{S *} & =\frac{k(1-\beta)(\beta M+\beta(1-\beta) \delta)(M-\beta \delta)}{(k+\beta M+\beta(1-\beta) \delta)^{2}} ; i=1,2 .
\end{aligned}
$$

The following lemma presents some useful properties of the equilibrium effort level in the stand-alone structure.

Lemma 2 The equilibrium effort level in the stand-alone structure, $e^{S *}$, is increasing in the level of project payoff $M$, in the employee bargaining power $\beta$, and in the degree of human capital mobility $\delta$ :

$$
\text { i) } \left.\left.\frac{\partial e^{S *}}{\partial M}>0, \quad i i\right) \frac{\partial e^{S *}}{\partial \beta}>0, \quad i i i\right) \frac{\partial e^{S *}}{\partial \delta}>0 .
$$

Furthermore: (iv) $\frac{\partial^{2} e^{S *}}{\partial \delta \partial M}<0$.

The level of effort is increasing in both project payoff $M$ and employee bargaining power $\beta$, since both parameters increase employee expected profits from exerting effort to innovate, giving (i) and (ii). In addition, since the two firms compete for employee human capital, this creates an outside option for the employees, with a positive effect on incentives to exert effort, giving (iii). Interestingly, the positive effect of the employee outside option $\delta$ on incentives is stronger when innovation payoff $M$ is smaller, giving (iv). The intuition is that smaller $M$ implies lower employee effort, all else constant. Hence, the benefit of the outside option in terms of improving employee incentives is greater for lower values of $M$. 
It is straightforward to show that the first-best level of effort in the stand-alone structure is given by $e_{F B}^{S *}=\frac{M}{M+k}$. Comparing $e^{S *}$ to $e_{F B}^{S *}$ reveals that there is always underinvestment in equilibrium since contracts are incomplete and the employees share part of the ex post surplus with their firms. Importantly, the employee outside option $\delta$ reduces the extent of underinvestment by increasing the rent extraction ability of the employees, reflected by the property that $\frac{\partial\left(e_{F B}^{S *}-e^{S *}\right)}{\partial \delta}<0$.

Having examined the effect of employee outside option on employee effort, we now turn our attention to its effect on firm expected profits. Firm expected profits depend on employee effort and ex-post firm payoffs from developing employee innovations. If both employees are successful in generating an innovation, competition in the product market drives innovation payoff to zero for both firms. If only one employee is successful, the successful employee uses his outside option of moving to the competing firm to extract greater rents from his current firm, reducing his firm's ex post rents. Although the employee outside option has a negative effect on ex post firm payoffs, its overall effect on firm expected profits can be positive if employee bargaining power is sufficiently low. The intuition is that, in the absence of the outside option, a low employee bargaining power implies weak incentives and, thus, a low probability of obtaining an innovation. Hence, in such case, employee outside option is more desirable in terms of its role in improving employee incentives. In addition, when $\beta$ is low, the additional rent extraction ability of the employee is not too costly for the firm. This can be seen by noting that the cost of an increase in $\delta$ in terms of reducing ex post firm payoff given by $(1-\beta)(M-\beta \delta)$ is smaller for smaller $\beta$. The following lemma presents the net effect of the employee outside option on firm expected profits formally.

Lemma 3 Firm expected profits are increasing in $\delta$ if employee bargaining power is sufficiently low, that is, $\frac{\partial \pi_{F_{i}}^{S *}}{\partial \delta} \geq 0, i=1,2$ for $\beta \leq \beta^{S}$ where $\beta^{S}$ is defined in the Appendix.

This result suggests that for sufficiently low values of employee bargaining power the firms benefit from an increase in $\delta$ even though it increases the rents extracted by the employees. One interesting implication from this result is that the firms may benefit from taking actions to 
increase the outside option of their employees. We examine this possibility in detail in Section 5 .

\subsection{The merger}

If the two firms decide to merge, the post-merger firm retains both employees. ${ }^{14}$ As before, after the firms make the organization structure choice, each employee exerts effort $e_{i}^{M} i=1,2$, which determines the probability of generating an innovation. We assume that the innovations generated by the two employees are perfect substitutes, and that the post-merger firm implements only one of the employee innovations in the case both employees generate an innovation. ${ }^{15}$

The merger has implications both for the level of product market competition and the level of competition for employee human capital. Recall that under the stand-alone structure, when the employees of both firms are successful in generating an innovation, competition in the product market drives payoffs to zero. After the merger, in contrast, the post-merger firm obtains a positive payoff from employee innovations even when both employees are successful, since the merger combines previously competing two firms into a single firm with a monopoly position. The merger also affects competition for employee human capital. This is because after the merger there is no rival firm to which the employees can transfer their innovation. This implies that the employees lose their outside option when they bargain with the post-merger firm. ${ }^{16}$

Notably, the merger not only eliminates the outside option of the employees, but it also creates an outside option for the post-merger firm. This is because when both employees are successful, the firm has two employee innovations to choose from. This means that, if bargaining with one employee breaks down, the firm still has the option of developing the other employee's innovation. Hence, the presence of a second employee provides the firm with an "outside option", which allows the firm to extract greater rents from each employee, compared to the stand-alone

\footnotetext{
${ }^{14}$ It is straightforward to prove that, under our assumption $M<k$, it is optimal for the post-merger firm to retain both employees rather than downsizing by firing one of them.

${ }^{15}$ See Rotemberg and Saloner (1994) for a similar assumption.

${ }^{16}$ Recall that our assumption that the merger eliminates competition in the product market and employee outside option is for analytical tractability. All we need for our results is that the merger reduces competition in the final good market and in the market for employee human capital.
} 
structure where the firms have no outside option. ${ }^{17}$

Finally, the merger provides a co-insurance benefit from having two employees. In other words, the post-merger firm is able to develop an innovation as long as at least one of the employees is successful, which can be greater than the probability of developing an innovation for a stand-alone firm with only one employee. ${ }^{18}$

We now proceed with the derivation of firm and employee payoffs under the merger. First, consider the simpler case where only one employee generates an innovation. Since the post-merger firm is a monopolist, and only one employee has an innovation, both the firm and the employee have zero outside options when they bargain. Thus, the employee will obtain payoff $\beta M$, and the firm will retain the remainder payoff, $(1-\beta) M$. Notice that, with respect to the stand-alone structure, the employee loses his outside option $\delta$.

If both employees generate an innovation, we assume that the firm selects randomly and with equal probability one of the two employee innovations to develop. The selected employee, say employee $i$, will then bargain with the firm for his share of the surplus. As before, the two parties make alternating offers under the threat that the bargaining process breaks down with a certain exogenous probability. The difference with the stand-alone structure is that while bargaining with employee $i$, the firm has the option of developing the innovation generated by employee $j$, if bargaining between the firm and employee $i$ breaks down. Thus, the payoff from bargaining with employee $j$ represents the firm's outside option when bargaining with employee $i$. Hence, the merger creates an outside option for the post-merger firm.

We can determine the payoffs of the bargaining game between the firm and employee $i$ by proceeding backwards. If bargaining with employee $i$ breaks down, the firm bargains with employee

\footnotetext{
${ }^{17}$ Note that the observation that the post-merger firm extracts greater rents when it employs more than one employee is similar to the result in Stole and Zwiebel (1996a and 1996b), who show that firms may overemploy in order to gain a bargaining advantage in wage negotiations with their employees.

${ }^{18}$ Note that if the success probability $e$ of obtaining an innovation is exogenously given, the overall probability of an innovation is always greater in the merger scenario than in the stand-alone scenario. However, given that the merger has adverse effects on endogenous success probability of obtaining an innovation, the post-merger firm can experience a lower innovation probability.
} 
$j$. In this second bargaining game, both employee $j$ and the firm have zero outside options. The employee and the firm will therefore divide the joint surplus according to their bargaining power, obtaining $\beta M$ and $(1-\beta) M$, respectively.

The firm's payoff from bargaining with employee $j$, given by $(1-\beta) M$, represents the firm's outside option while bargaining with employee $i$. In contrast, employee $i$ has no outside option given that there are no other firms to which he can transfer his innovation. This implies that employee $i$ 's payoff from bargaining with the firm is now equal to $\beta(M-(1-\beta) M)=\beta^{2} M$. Furthermore, since employee $i$ 's innovation is chosen with probability $\frac{1}{2}$, his expected payoff is $\frac{\beta^{2} M}{2}$. Correspondingly, the firm's payoff is given by $(1-\beta) M+(1-\beta)(M-(1-\beta) M)=\left(1-\beta^{2}\right) M$. Since $\left(1-\beta^{2}\right) M>(1-\beta) M$, the post-merger firm with two employees extracts greater rents than each stand-alone firm with one employee only.

Importantly, employee and firm payoffs when both employees are successful in the merger scenario are different from those in the stand-alone structure for two reasons: First, the monopoly position of the firm implies that the total payoff from employee innovations is always $M$ as long as at least one employee succeeds in generating an innovation. Second, in the merger scenario the ability to play the employees against each other creates a bargaining advantage for the postmerger firm and allows the firm to extract greater rents from the employees.

In anticipation of his payoff from bargaining with the firm, given the effort level $e_{j}^{M}$ chosen by employee $j$, employee $i$ chooses his effort level, $e_{i}^{M}$, by maximizing his expected profits, denoted by $\pi_{E_{i}}^{M}$ :

$$
\max _{e_{i}^{M}} \pi_{E_{i}}^{M} \equiv e_{i}^{M} e_{j}^{M} \frac{\beta^{2} M}{2}+e_{i}^{M}\left(1-e_{j}^{M}\right) \beta M-\frac{k}{2}\left(e_{i}^{M}\right)^{2} ; i, j=1,2 ; i \neq j .
$$

The expected profits of the post-merger firm denoted by $\pi_{F}^{M}$ are given by:

$$
\pi_{F}^{M} \equiv e_{i}^{M} e_{j}^{M}\left(1-\beta^{2}\right) M+e_{i}^{M}\left(1-e_{j}^{M}\right)(1-\beta) M+e_{j}^{M}\left(1-e_{i}^{M}\right)(1-\beta) M ; i, j=1,2 ; i \neq j
$$

The first-order condition of (7) provides employee $i$ 's optimal response, given employee $j$ 's effort choice, as follows:

$$
e_{i}^{M}\left(e_{j}^{M}\right)=\frac{\beta M\left(2-e_{j}^{M}(2-\beta)\right)}{2 k} ; i, j=1,2 ; i \neq j
$$


From (9), it can be immediately seen that employee $i$ 's effort is a decreasing function of employee $j$ 's effort, due to the firm's ability to extract greater surplus from each employee in the state where both employees are successful.

The following lemma presents the equilibrium level of employee effort in the merger scenario, and the expected profits of the employees and the post-merger firm.

Lemma 4 The Nash-equilibrium of the effort subgame under the merger is given by:

$$
e_{i}^{M *}=e_{j}^{M *}=e^{M *} \equiv \frac{2 \beta M}{2 k+\beta(2-\beta) M}
$$

The corresponding expected profits of the employees and the firm are given by:

$$
\begin{aligned}
\pi_{E_{i}}^{M *} & =\frac{2 k \beta^{2} M^{2}}{(2 k+\beta(2-\beta) M)^{2}}, i=1,2 ; \\
\pi_{F}^{M *} & =\frac{4 \beta(1-\beta)(2 k+\beta M) M^{2}}{(2 k+\beta M(2-\beta))^{2}} .
\end{aligned}
$$

Relative to the stand-alone structure, the merger has three effects on employee incentives to exert effort. The first is positive, and due to the merger's role in eliminating competition in the product market. In the state where both employees are successful, each employee obtains a positive payoff (as opposed to obtaining zero payoff in the stand-alone structure), and exerts higher effort, all else constant. The magnitude of this effect increases in $M$. The second effect is negative, and stems from the fact that the merger eliminates competition for employee human capital. Since after the merger there are no rival firms to which the employees can transfer their innovation, they lose their outside option when they bargain with the firm, obtain lower rents, and have lower incentives to exert effort. The magnitude of this negative effect is stronger for lower values of $\delta$. The third effect is again negative, and arises from the ability of the post-merger firm to induce competition between the employees in the state where both employees are successful. Having two employees to bargain with creates an outside option for the post-merger firm and allows the firm to extract a greater surplus from each employee. In addition, the firm's ability to choose from two employee innovations implies that for each employee there is only $50 \%$ chance that his innovation will be selected for development, further reducing employee expected rents. 
The following proposition compares the level of employee effort in the merger scenario to that in the stand-alone structure.

Proposition 1 The level of effort under the stand-alone structure is greater than that under the merger if and only if $M \leq \bar{M}$ and $\delta \geq \bar{\delta}$ where $\bar{M}$ and $\bar{\delta}$ are defined in the Appendix. Furthermore, $\frac{\partial \bar{M}}{\partial \beta}<0$.

The net impact of the stand-alone structure, relative to the merger, on employee effort is the outcome of two opposing effects. On the one hand, the stand-alone structure lowers the payoff from the innovation when both employees are successful, due to competition in the product market, with a negative effect on incentives. The magnitude of this negative effect increases with $M$. On the other hand, the stand-alone structure creates competition for employee human capital and allows the employees to extract greater rents, with a positive effect on their effort incentives. The magnitude of this positive effect increases in $\delta$. When the value of the outside option is sufficiently large and when the level of product market competition is sufficiently low, that is, when $\delta \geq \bar{\delta}$ and $M \leq \bar{M}$, the positive effect dominates the negative one, and the level of effort in the stand-alone structure is greater than that under the merger.

Furthermore, the threshold level $\bar{M}$ is lower when employee bargaining power is greater. This means that the merger is more likely to lead to greater effort when employee bargaining power is already sufficiently large, and thus when the benefit of the outside option on employee effort is not too desirable.

We now turn to the firms' decision to merge or to remain stand-alone. The merger affects firm expected profits in two ways: ex ante, through its impact on employee incentives and ex post through the impact on the post-merger firm's payoff from employee innovations. As we discussed above, while the merger's overall effect on employee incentives is ambiguous, its effect on the firm's ex-post payoff from employee innovations is always positive. This is because the merger eliminates both competition in the product market and competition for employee human capital, leading to an increase in ex post payoffs for the firm. Moreover, the merger creates an outside option for the firm in case both employees are successful, allowing the firm to extract 
greater surplus from the employees. The following proposition characterizes the firms' choice of organization structure.

Proposition 2 (i) If $0<\beta \leq \beta^{S}$, there are unique values $M_{C}$ and $\delta_{C}$, defined in the Appendix, such that for $M \leq M_{C}$ and $\delta \geq \delta_{C}$ the two firms obtain greater expected profits under the standalone structure than the merger and, hence, choose the stand-alone structure. (ii) If $\beta>\beta^{S}$ the two firms obtain greater expected profits with the merger. Furthermore, $\frac{\partial M_{C}}{\partial \beta}<0$, and $\frac{\partial M_{C}}{\partial k}>0$.

Since ex ante firm expected profits depend on employee effort and firms' ex post payoffs from employee innovations, intuitively one can expect that the firms obtain greater expected profits in the stand-alone structure only when its benefits in terms of greater employee effort are sufficiently valuable to the firm and when it does not cost too much for the firms due to the employees' greater rent extraction ability.

Proposition 2 confirms this intuition. When employee bargaining power is sufficiently large, that is, when $\beta>\beta^{S}$, employee incentives to exert effort are already strong even with no employee outside option. Hence, the two firms find it desirable to merge to enjoy the co-insurance benefit and a greater market power, given that the merger has only a negligible negative effect on employee incentives. In contrast, when employee bargaining power is low, that is, when $\beta \leq \beta^{S}$, providing the employees with better incentives becomes particularly important for the firms. This implies that the two firms prefer the stand-alone structure, provided that the benefit of the stand-alone structure on incentives, as measured by $\delta$ is sufficiently large, and its cost from potential loss of $M$ due to product market competition is not too large.

Finally, note that the threshold level $M_{C}$ is decreasing in $\beta$ and increasing in $k$. The first property confirms the earlier intuition regarding the importance of enhancing employee incentives especially when employees have a low bargaining power. If we interpret $k$ as a measure of the human capital intensity of the innovative project, the second property implies that the firms are more likely to choose the stand-alone structure in industries characterized by a greater level of human capital intensity. In such industries, motivating employee effort is key to innovation generation, and hence, the stand-alone structure becomes more desirable relative to mergers due 
to its positive effect on employee rent extraction ability. Conversely, the merger is more likely to be profitable in industries with a lower human capital intensity and greater physical capital intensity, that is, in sectors where motivating employee incentives is less critical.

\section{Organization Structure and Firm Investment Incentives}

Our analysis so far has assumed that innovation generation requires only employee effort, and hence, focused on the effect of the organizational structure on employee incentives to exert innovation effort. In this section, we extend our analysis such that we model firm incentives to invest in innovation, and show that firm organization structure has an important effect on the innovation incentives of the firms as well.

We extend our basic model such that a necessary condition for employees to generate an innovation is that their firms make an initial investment before employees exert costly effort. This investment can be viewed as firms investing in physical assets that are necessary for employees to be able to generate new innovative ideas. Alternatively, it can be seen as firms investing in employee human capital, such as innovation-specific training that employees need to receive before working towards innovative projects.

We analyze firm incentives in two different organization structures. In the first one, the two firms operate as stand-alone and, as before, face competition both in the product market and in the market for employee human capital. In the second structure, we consider a firm with a larger scale with two employees (or divisions) and a monopoly position in the product market. In addition, we assume that the two-divisional firm has a synergy advantage due to economies of scale in financing the initial investment required to operate two divisions. We then compare firm incentives to make the initial investment under the two organization structures, and show that, under certain parameter values, the firms in the stand-alone organization structure have indeed the incentives to invest in innovation while the larger firm does not have sufficient incentives to invest in innovation. This result is remarkable since the two firms prefer operating as a stand-alone firm as opposed to operating as a larger firm enjoying economies of scale and no competition. 
We modify our model as follows. At $t=0$, if the two firms operate stand-alone, each firm must incur an initial investment $I>0$ so that its employee has access to the resources necessary to work towards an innovative idea. In contrast, if there is only one firm in the product market operating as a monopolist with two employees/divisions, the necessary initial investment is $K I$. We assume $1<K \leq 2$ which implies that the larger firm, relative to the stand-alone firms, enjoys economies of scale due to having two employees, or operating two divisions.

The following proposition presents that there is an equilibrium in which the stand-alone structure, where each firm incurs $I$ is profitable and thus viable, while the market structure where the larger firm incurs $K I$ is not profitable and, thus not viable. In other words, in this equilibrium, the stand-alone structure where the two smaller firms compete in the product market leads to positive firm expected profits, net of investment costs $I$ while the monopoly structure does not provide sufficient incentives to incur the initial cost $K I$ despite the cost advantage of the larger firm.

Proposition 3 Let $\beta \leq \beta^{S}, \delta_{C} \leq \delta \leq M$ and $M \leq M_{C}$. There exists $I_{1}$ and $I_{2}$ defined in the appendix such that if $I_{1}<I<I_{2}$ the stand-alone firms invest in innovation while the larger monopoly firm does not.

Proposition 3 has several implications for the organization and market structure of early stage industries characterized by a greater degree of hold-up problem where employees could extract very small rents from the innovative ideas they generate. First, it suggests that in such industries firms with smaller size have greater incentives to invest in innovation. This is because the standalone structure results in stronger employee incentives, which in turn increases firm profitability and feeds back into the firms' willingness to invest in innovation.

The second implication of Proposition 3 is that in early stage industries exposed to the holdup problem, a competitive market may be profitable in terms of firm expected profits than a monopoly structure. This implies that in such industries innovation is more likely to thrive in a competitive setting while a monopolistic structure may stifle innovation. The intuition for this result is that the competitive setting provides the employees with stronger incentives to exert 
effort, increases firm expected profits, and hence, increases the willingness of the firms to invest in innovation in the first place. In the monopoly structure, however, since employee mobility is lower, and the employees are more likely to be help up by the firm, employee effort and innovation probability are lower. This, in turn, reduces the firm's willingness to invest in innovation.

\section{Spin-offs}

Section 2 of our paper showed that, under certain conditions, the merger leads to lower firm profits than the stand-alone structure. This result implies that a firm with two divisions will benefit from a spin-off transaction by establishing one of the divisions as a new firm even if by doing so the firm creates its own competition. After the spin-off, the parent firm has only one employee/division and hence loses its bargaining advantage from having two employees. In addition, there is now a new independent firm to which the employee of the parent firm can transfer his human capital. Although both of these effects are costly for the parent firm ex post, they may still lead to greater firm value by increasing ex ante employee incentives. These results are consistent with the empirical findings that announcement of spin-off transactions generate positive cumulative abnormal returns for parent firms (Hite and Owers, 1983, Miles and Rosenfeld, 1983, and Schipper and Smith 1983).

It will be straightforward to modify our model such that the new firm established through the spin-off does not compete in the same product market as the parent firm. In such a situation, on one hand, the incentives for the spin-off will be greater given that the parent firm does not face competition from the new firm. On the other hand, if the new established firm is unrelated to the parent firm, the employee of the parent firm will not gain a significant increase in his rent extraction ability since the value of his human capital at the new firm will be rather low given that the new firm is in a different product market than the parent firm. Hence, both the costs and the benefits of undertaking a spin-off transaction will be smaller the more unrelated the spun-off division to the parent firm, with an ambiguous overall effect.

Our results from Section 3 on firm investment incentives has also implications for spin-offs. 
Our analysis suggests that a two-divisional firm will have greater investment incentives after a spin-off, although the spin-off eliminates advantages similar to those of an internal capital market. In our model, the firm with two employees enjoys two benefits. The first is the coinsurance benefit, associated with internal capital markets, in that the firm can create value even if one employee fails. In other words, instead of relying on only one employee/division, the firm with two divisions may experience a higher probability of being able to bring a new product to the market. The second benefit is that the firm enjoys economies of scale from operating two similar divisions under the same roof. Our analysis suggests that it is possible that the positive effect of the spin-off on employee incentives outweighs these two benefits, and firm expected profits can be greater after the spin-off. This, in turn, reinforces the investment incentives of the parent firm. This result is consistent with Dittmar and Shivdasani (2000) who show that parent firms tend to increase their rate of investment after they divest businesses. Our paper provides a potential explanation for this finding that reducing firm size improves employee incentives and employee productivity (effort), which, in turn, increases firm investment incentives.

Our analysis has also implications for employee spin-outs where employees of existing firms leave their current firm to start their own business. Our paper suggests that especially human capital intensive firms in newly developing industries can benefit from spin-out transactions although new firms started by current employees may create competition for existing firms both in the product market and for employee human capital.

\section{Human capital mobility}

In the previous sections we showed that the stand-alone structure can be more desirable than the merger due to its positive effect on the ability of the employees to move to a rival firm, even if this benefit comes at the expense of paying greater employee rents and facing competition in the product market. This result suggests that the firms in the stand-alone structure may find it desirable to take ex ante actions that increase the ex post level of human capital mobility, as measured by parameter $\delta$. 
Firms can affect the degree of transferability of employee human capital in a number of ways. For example, the stringency of the no-compete agreements that firms impose on their employees at the time they join the firm influences employee ability to move to competing firms. Alternatively, the location choice of firms has an effect on employee mobility in that employees of firms located within industry clusters will find it easier to move from one firm to another. In addition, firms can cooperate and jointly agree to select common industry standards, such as compatible technologies and protocols, so that employee skills and human capital can be valuable outside their current firm. Finally, firms can ex ante coordinate policies on hiring employees from competing firms, making employee transfer across rival firms easier or more difficult.

In this section, we examine firms' ex ante incentives to increase employee mobility, characterized in our model by a high level of $\delta$, or impede employee mobility by choosing a low level of $\delta$. We modify the basic model as follows. At $t=0$, the two firms individually and simultaneously choose the degree of mobility of their employees, with firm $i$ setting $\delta_{i}$ with $0 \leq \delta_{i} \leq M$ in order to maximize its own expected profits. For simplicity, we assume that the firms do not incur any cost in choosing $\delta_{i}>0 .{ }^{19}$ The rest of the game remains as in Section 2 .

Proceeding backward, employee $i$ exerts effort $e_{i}^{S}\left(\delta_{i}, \delta_{j}\right)$ in order to maximize his expected profits, given by $\pi_{E_{i}}^{S}\left(\delta_{i}, \delta_{j}\right)$ :

$$
\max _{e_{i}^{S}\left(\delta_{i}, \delta_{j}\right)} \pi_{E_{i}}^{S}\left(\delta_{i}, \delta_{j}\right) \equiv e_{i}^{S}\left(1-e_{j}^{S}\right)\left(\beta M+\beta(1-\beta) \delta_{i}\right)-\frac{k}{2}\left(e_{i}^{S}\right)^{2} ; i, j=1,2 ; i \neq j
$$

The first-order condition of (13) provides employee $i$ 's optimal response, given employee $j$ 's choice of effort, as follows:

$$
e_{i}^{S}\left(e_{j}^{S}\right)=\frac{\left(1-e_{j}^{S}\right)\left(\beta M+\beta(1-\beta) \delta_{i}\right)}{k} ; i, j=1,2 ; i \neq j .
$$

Setting $e_{j}^{S}=e_{i}^{S}$, and solving (14) for $e_{i}^{S}$ yields the Nash-equilibrium level of effort chosen by the two employees, denoted by $e_{i}^{S *}\left(\delta_{i}, \delta_{j}\right)$ :

$$
e_{i}^{S *}\left(\delta_{i}, \delta_{j}\right)=\frac{\left(\beta M+\beta(1-\beta) \delta_{i}\right)\left(k-\beta M-\beta(1-\beta) \delta_{j}\right)}{k^{2}-\left(\beta M+\beta(1-\beta) \delta_{i}\right)\left(\beta M+\beta(1-\beta) \delta_{j}\right)} .
$$

\footnotetext{
${ }^{19}$ It is possible to extend the analysis such that it is costly for the firms to choose a positive level of $\delta$.
} 
By direct differentiation, it is easy to verify that equilibrium effort level for employee $i, e_{i}^{S *}\left(\delta_{i}, \delta_{j}\right)$, is increasing in the degree of his own human capital mobility $\delta_{i}$, and decreasing in the degree of employee mobility of the employee at the rival firm, $\delta_{j}$. This observation implies that by increasing the mobility of its own employee, each firm can not only improve the effort level of its own employee, but also lower the effort level at the rival firm. Hence, an increase in $\delta_{i}$ provides firm $i$ with a strategic advantage by decreasing the innovation effort at firm $j$.

Given the level of employee effort, $e_{i}^{S *}\left(\delta_{i}, \delta_{j}\right)$, firm $i$ chooses $\delta_{i}$ to maximize its expected profits, denoted by $\pi_{F_{i}}^{S}\left(\delta_{i}, \delta_{j}\right)$ :

$$
\begin{aligned}
\pi_{F_{i}}^{S}\left(\delta_{i}, \delta_{j}\right) & \equiv e_{i}^{S}\left(1-e_{j}^{S}\right)(1-\beta)\left(M-\beta \delta_{i}\right) ; i, j=1,2 ; i \neq j \\
\text { s.t. } 0 & \leq \delta_{i} \leq M
\end{aligned}
$$

There are three factors affecting firm $i^{\prime} s$ choice of $\delta_{i}$. The first is the direct effect of an increase in $\delta_{i}$ on employee $i$ 's incentives to exert effort: an increase in $\delta_{i}$ increases the probability that firm $i$ obtains an innovation. The second factor is strategic, and derives from the fact that an increase in $\delta_{i}$ leads, all else equal, to a lower level of employee effort at the rival firm, creating a strategic advantage for firm $i$. Since firm $i$ obtains greater payoff when it is the sole innovator, which happens with probability $e_{i}^{S}\left(1-e_{j}^{S}\right)$, these two factors always lead firm $i$ to prefer a greater value of $\delta_{i}$. Because the benefit of an increase in $\delta$ in improving the innovation probability is greater for lower values of employee bargaining power, the two firms will find it most desirable to enhance employee mobility for lower values of $\beta$. The third factor is negative, and due to the impact of an increase in $\delta_{i}$ on firm ex post payoffs from employee innovations. A greater value of $\delta_{i}$ increases the rent extraction ability of employee $i$ and, therefore, lowers firm $i^{\prime}$ s ex-post payoff, as reflected by the term $M-\beta \delta_{i}$ in (16). All else equal, the cost of increasing $\delta_{i}$ for firm $i$, in terms of the loss of rents to the employee, is smaller for lower values of employee bargaining power $\beta$. The following proposition characterizes the Nash-equilibrium level of $\delta_{i}$. 
Proposition 4 The unique Nash-equilibrium level of $\delta_{i}$ denoted by $\hat{\delta}^{*}$, is given by

$$
\hat{\delta}_{i}^{*}=\hat{\delta}_{j}^{*}=\hat{\delta}^{*} \equiv\left\{\begin{array}{cc}
M & \text { if } \beta \leq \hat{\beta}_{1} ; \\
\hat{\delta} \equiv \frac{k^{2}-M^{2} \beta-k \sqrt{k^{2}-M^{2}}}{\beta(1-\beta) M} & \text { if } \hat{\beta}_{1}<\beta \leq \hat{\beta}_{2} ; \\
0 & \text { if } \beta>\hat{\beta}_{2},
\end{array}\right.
$$

with $\partial \hat{\delta} / \partial \beta<0$ and $\partial \hat{\delta} / \partial M>0$ where $\hat{\beta}_{1}$ and $\hat{\beta}_{2}$ are defined in the Appendix. Furthermore, $\partial \hat{\beta}_{1} / \partial M \geq 0$ and $\partial \hat{\beta}_{2} / \partial M \geq 0$.

The Nash-equilibrium level of $\delta$ is (weakly) decreasing in employee bargaining power $\beta$. This is because the importance of improving employee incentives by providing better outside options is greater at lower levels of employee bargaining power. In addition, as noted above, the cost to the firms of increasing $\delta$ is smaller at lower levels of employee bargaining power. These two observations together imply that $\hat{\delta}$ is a decreasing function of $\beta$.

The property that the Nash-equilibrium level of $\delta$ is (weakly) increasing in the payoff $M$ is an implication of the direct effect of employee mobility on employee incentives to innovate, and its strategic effect discussed above. The intuition is that, under product market competition, the firms obtain the monopoly payoff $M$ only in the state where their employee is successful while the employee at the rival firm fails. This means that each firm has the desire to increase the probability of this state by promoting the effort of its own employee and reducing the effort of the employee at the competing firm. The benefit of increasing the probability of this outcome is greater when the potential payoff $M$ from the innovation is larger, leading to a positive relation between employee mobility $\delta$ and project payoff $M$. Finally, consistent with this argument, we obtain $\partial \hat{\beta}_{1} / \partial M \geq 0$ and $\partial \hat{\beta}_{2} / \partial M \geq 0$.

Our analysis in this section suggests that firms can benefit from being closer to similar firms to improve employee incentives, and their desire to do so is greater when employees are more vulnerable to opportunistic behavior by their firms, that is, when they have lower bargaining power. In addition, firms are less likely to adopt clauses restricting employee mobility especially when there is more to gain from being ahead of the competing firms, that is, when payoff $M$ is greater. Finally, our analysis has the implication that firms individually may find it desirable 
to establish common industry standards and protocols to facilitate employee mobility within an industry.

\section{Empirical implications}

In our paper employee ex post rents from the development of new products depend on employee bargaining power $\beta$. One potential interpretation of parameter $\beta$ is that it depends on the severity of the hold-up problem that employees are subject to in ex post negotiations with their firms. Hence, lower $\beta$ implies lower employee rents and a greater degree of the hold-up problem.

The second critical parameter in our model is the ex post payoff from employee innovations measured by $M$. This parameter can be interpreted as the size of the industry for new products. It may also be seen as a function of the failure probability of developing new products (see footnote 10). This leads to the interpretation that early stage industries with smaller market size and greater failure probability of developing new products will be characterized with smaller value of $M$.

The third important parameter of our model is $k$, the unit cost of exerting innovation effort. Since, all else constant, a higher value of $k$ implies a lower success probability of generating a new product, riskier projects with larger failure rates and greater human capital intensity will have greater $k$.

The main results of our paper lead to the following predictions.

(i) Stand-alone structures will lead to greater innovation probability, relative to mergers, when employees are more prone to the hold-up problem. This prediction is consistent with the finding in Seru (2007) that single-division firms are more innovative than multidivisional firms. Our model suggests that the difference in innovation output between single and multidivisional firms will be greater when the extent of the hold-up problem employees are subject to is larger.

(ii) Stand-alone structures will result in greater innovation probability in early stage industries with smaller market size and greater risk of developing new products. This prediction is due to our result that enhancing employee incentives through employee outside option is most valuable 
for lower values of $M$.

Our result that the stand-alone structure in our model is more innovation-friendly than mergers for lower values of $M$ also suggests that firms will gain from being closer to similar firms, especially in emerging industries with smaller market size and greater failure probability, leading to the following prediction:

(iii) Industry clusters where firms in similar product markets locate within close geographical distances are more likely to emerge in earlier stages of an industry. As the industry develops and becomes more mature, the incentives of firms within an industry cluster to merge will be greater.

In our model, in equilibrium the firms are more likely to choose the stand-alone structure than the merger for lower values of $M$. As $M$ increases, the incentives to merge and reduce product market competition increase. Related to this prediction, in recent work Almazan et al. (2009) show that firms located within industry clusters undertake more acquisitions than other firms in their industry located outside clusters. Our paper suggests that the incentives for mergers taking place between firms located within the same cluster will increase when the desire to reduce competition becomes more important. In newly developing industries where competitive pressures are not too pressing, firms within industry clusters will prefer the stand-alone structure to promote stronger employee incentives.

(iv) Stand-alone structures are more likely in human capital intensive industries while mergers are more likely in physical capital intensive industries. If we modify our model such that the success probability $e$ of innovating new products is constant and exogenously given, the two firms will always merge since the merger's negative effects on incentives will disappear. This observation suggests that mergers are more desirable in industries with "old economy" firms where value creation largely depends on the physical assets of the firm while in industries with "new economy" firms where human capital is one of the most critical inputs of value creation, mergers will be less desirable. Consistent with these interpretations, anecdotal evidence shows that mergers are largely uncommon in the private equity, venture capital, and investment banking industry where human capital is indeed very important for value creation. Although two investment banks can 
merge and increase their pricing power in the product market in their underwriting business, our model suggests that keeping competition alive in the product market and creating competition for their own employees may lead to greater profitability than merging to increase market power in the product market.

(v) Firm investment in innovation will be greater under competition than under monopoly in early stage industries with smaller size where employees are subject to a greater degree of the hold-up problem. Section 3 of our paper shows that when employee bargaining power and project payoff from employee innovations are sufficiently low, firm incentives to invest in innovation are greater in the competitive market structure than in the monopoly structure. Greater innovation incentives for firms, in turn, translate into a greater innovation output, and greater profitability of the competitive structure, relative to the merger. Related to this result, our model also implies that multidivisional firms can improve employee incentives and innovation output by undertaking a spin-off transaction even though doing so creates competition in the product market, competition for employee human capital, and eliminates the scale advantage of being a larger firm. Alternatively, our analysis suggests that established firms could benefit from encouraging their employees to start independent new firms, which may end up competing with them in the product market. Hence, perhaps counterintuitively, creating their own competition may benefit them through stronger employee incentives.

(vii) Choosing similar and compatible technology standards, and not imposing no-compete agreements will have a positive effect on employee incentives to innovate when employees are subject to greater degree of the hold-up problem. This result is consistent with the view in Gilson (2004) that one explanation for superior performance of Silicon Valley relative to Boston's Route 128 could be that California does not enforce no-compete clauses while Massachusetts does. It is also consistent with the evidence in Samila and Sorenson (2009) that the use of no-compete agreements significantly hinders innovation activity and growth.

The prediction of our model on the importance of enhancing employee mobility is interesting in the context recent research summarized in MIT Sloan Management Review/WSJ, Oct 26, 
2009. This study argues that the best way to retain valuable employee human capital is to make it easier for employees to leave. Providing employees with the skill and experience set which make them more attractive in the job market not only helps firms to retain valuable employees, but also make employees more valuable within the firm. The study finds that executives plan to stay longer at firms that provide greater opportunities to enhance their employability. This finding is consistent with our analysis that although enhancing employability of employees exposes firms to greater competition and makes it more costly to retain employees, it can still increase firm profitability by making employees more innovative and valuable within their firm.

\section{Conclusions}

Many mergers are driven by the desire to develop new products and to enter into new product markets. Our paper shows that especially in human capital intensive industries, mergers might have a negative effect on employee incentives to innovate new products as well as firm incentives to invest in innovation. On one hand, mergers reduce the external product market competition and increase expected payoffs from employee innovations. On the other hand, by reducing the number of firms in the product market, mergers limit employee ability to go from one firm to another with a negative effect on incentives. Moreover, mergers create internal competition between the employees of the post-merger firm, with an additional negative effect on incentives to innovate. When the negative effects of the merger on incentives are sufficiently large, firms are better off competing in the product market and competing for employee human capital rather than merging and eliminating competition. In other words, firms prefer not to merge and bear competition in the product market to maintain stronger employee incentives.

Our results on the negative effect of mergers on employee incentives have interesting implications for spin-off transactions. Our paper suggests that a multidivisional firm can create value by undertaking a spin-off transaction since reducing firm size can have a positive effect on employee incentives. This incentive benefit can be sufficiently strong that the spin-off leads to greater

firm profits even at the loss of the co-insurance benefit of an internal capital market within the 
multidivisional firm.

We also study how firms can improve employee mobility through their location choices and use of no-compete agreements. Our paper shows that firms will choose to locate closer to similar firms in order to enhance employee incentives, although doing so exposes them to greater competition in the product market and greater competition for employee human capital. Similarly we show that firms will improve employee mobility by adopting less restrictive no-compete agreements, or by locating in regions which do not enforce such agreements. Interestingly, the desire to do so is greater when there is more to gain from being ahead of the competing firms.

Our paper focuses mainly on horizontal mergers between firms operating in similar product markets while it is silent about mergers across unrelated industries. Similarly, firms in our model are homogenous in the sense that when merged into a single firm, there are no complementarities between them. It would be interesting in future research to study the effect of mergers on employee incentives if mergers combine two firms where employee innovations complement each other rather than being perfect substitutes.

\section{References}

[1] Almazan, A., de Motta, A. and S. Titman, Firm Location and the Creation and Utilization of Human Capital, Review of Economic Studies, 74, 1305-1327, 2007.

[2] Almazan, A., de Motta, A., Titman, S., and V.B. Uysal, Financial Structure, Acquisition Opportunities, and Firm Locations, forthcoming, Journal of Finance, 2009.

[3] Binmore, K., A. Rubinstein and A. Wolinski, The Nash Bargaining Solution in Economic Modelling, Rand Journal of Economics, 17, 176-188, 1986.

[4] Dittmar, A. K., and A. Shivdasani, Divestitures and Divisional Investment Policies, Journal of Finance, 58, 2711-2744, 2003. 
[5] Duranton, G. and D. Puga, Microfoundations of urban agglomeration economies in J. Vernon Henderson and Jacques François Thisse (eds.) Handbook of Regional and Urban Economics, Vol. 4, Amsterdam: North Holland, 2063-2117, 2004.

[6] Fulghieri, P. and L. Hodrick, Synergies and Internal Agency Conflicts: The Double-Edged Sword of Mergers, Journal of Economics and Management Strategy, 15, 549-576, 2006.

[7] Gertner, R.H., Scharfstein, D.F., and J.C. Stein, Internal versus External Capital Markets, Quarterly Journal of Economics, 109, 1211-1230, 1994.

[8] Gilson, R, J., The Legal Infrastructure of High Technology Industrial Districts: Silicon Valley, Route 128, and Covenants Not To Compete, New York University Law Review, 74 (3), 575-629, 1999.

[9] Grossman, S. and O. Hart, The Costs and Benefits of Ownership: A Theory of Vertical and Lateral Integration, Journal of Political Economy, 94, 691-719, 1986.

[10] Hart, O., The Market as an Incentive Mechanism, Bell Journal of Economics, 14, 366-382, 1983.

[11] Hart, O. and J. Moore, Property Rights and the Nature of the Firm, Journal of Political Economy, 98, 1119-1158, 1990.

[12] Hite, G., and J.E. Owers, Security price reactions around corporate spin-off announcements, Journal of Financial Economics, 12, 409-436, 1983.

[13] Hoberg, G., and G. Phillips, Product Market Synergies and Competition in Mergers and Acquisitions, University of Maryland, working paper, 2009.

[14] Matouschek, N. and F. Robert-Nicoud, The Role of Human Capital Investments in the Location Decision of Firms, Regional Science and Urban Economics, 35, 570-583, 2005.

[15] Mathews, D.R., and D.T. Robinson, Market Structure, Internal Capital Markets, and the Boundaries of the Firm, Journal of Finance, 63, 2703-2736, 2008. 
[16] Miles, J.A., and J.D. Rosenfeld, The effect of voluntary spin-off announcements on shareholder wealth, Journal of Finance, 38, 1597-1606, 1983.

[17] Rotemberg, J. J., and G. Saloner, Benefits of Narrow Business Strategies, American Economic Review, 84, 1330-1349, 1994.

[18] Rotemberg, J. J., and G. Saloner, Competition and Human Capital Accumulation: A Theory of Interregional Specialization and Trade, Regional Science and Urban Economics, 30, 373$404,2000$.

[19] Sampsa, S., and O. Sorenson, Non-Compete Covenants: Incentives to Innovate or Impediments to Growth, working paper, 2009.

[20] Scharfstein, D.F., Product-Market Competition and Managerial Slack, Rand Journal of Economics, 19, 147-155, 1988.

[21] Scharfstein, D.F., and J.C. Stein, The dark side of internal capital markets: Divisional rent seeking and inefficient investment, Journal of Finance, 55, 2537-2564, 2000.

[22] Schmidt, K.M., Managerial Incentives and Product Market Competition, Review of Economic Studies, 64, 191-213, 1997.

[23] Schipper, K., and A. Smith, Effects of recontracting on shareholder wealth: The case of voluntary spin-offs, Journal of Financial Economics, 12, 437-464, 1983.

[24] Seru, A., Do Conglomerates Stifle Innovation?, University of Chicago, working paper, 2007.

[25] Stein, J.C., Internal Capital Markets and the Competition for Corporate Resources, Journal of Finance, 52, 111-133, 1997.

[26] Stein, J. C., Agency, Information and Corporate Investment, in G. Constantinides, M.Harris, and R. Stulz (eds.), Handbook of the Economics of Finance, Elsevier, Amsterdam, 2003.

[27] Stole, L. and Z. H. Zwiebel, Intrafirm Bargaining Under Nonbinding Contracts, Review of Economic Studies, 63, 375-410, 1996a. 
[28] Stole, L. and Z. H. Zwiebel, Organizational Design and Technology Choice under Intrafirm Bargaining, American Economic Review, 86, 195-222, 1996b. 


\section{Appendix}

Proof of Lemma 1 From the reaction function (3), the Nash-equilibrium effort level $e^{S *}$ is obtained by setting $e^{S}=\frac{\left(1-e^{S}\right)(\beta M+\beta(1-\beta) \delta)}{k}$, and solving for $e^{S}$. Substituting (4) into (1) and (2) gives (5) and (6).

Proof of Lemma 2 Differentiating the equilibrium level of employee effort (4) with respect to $M$ yields $\frac{\partial e^{S *}}{\partial M}=\frac{\beta k}{(k+\beta M+\beta(1-\beta) \delta)^{2}}>0$, giving (i). Similarly, differentiating (4) with respect to $\beta$, and using $0<\beta<1$ and $\delta \leq M$ yields $\frac{\partial e^{S *}}{\partial \beta}=\frac{(M+\delta(1-2 \beta)) k}{(k+\beta M+\beta(1-\beta) \delta)^{2}}>0$, giving (ii). Differentiating (4) with respect to $\delta$, and using $0<\beta<1$, we obtain $\frac{\partial e^{S *}}{\partial \delta}=\frac{\beta(1-\beta) k}{(k+\beta M+\beta(1-\beta) \delta)^{2}}>0$, giving (iii). It is immediate to see from $\frac{\partial e^{S *}}{\partial \delta}=\frac{\beta(1-\beta) k}{(k+\beta M+\beta(1-\beta) \delta)^{2}}$ that $\frac{\partial^{2} e^{S *}}{\partial \delta \partial M}<0$, giving (iv).

Proof of Lemma 3 Differentiating the equilibrium level of firm profits (6) with respect to $\delta$ we obtain

$$
\frac{\partial \pi_{F_{i}}^{S *}}{\partial \delta}=\frac{\beta(1-\beta) k\left(\delta(M+2 k) \beta^{2}-(M+2 k)(M+\delta) \beta+M k\right)}{(k+\beta(M+(1-\beta) \delta))^{3}}
$$

$\frac{\partial \pi_{F_{i}}^{S *}}{\partial \delta}>0$ if and only if $P \equiv \delta(M+2 k) \beta^{2}-(M+2 k)(M+\delta) \beta+M k>0$. Since $P$ is a convex parabola in $\beta$, it has two roots given by

$$
\begin{aligned}
& \beta_{1} \equiv \frac{M+\delta}{2 \delta}-\frac{\sqrt{(M+2 k)\left(\left(M^{2}+\delta^{2}\right)(M+2 k)+2 M^{2} \delta\right)}}{2 \delta(M+2 k)} \\
& \beta_{2} \equiv \frac{M+\delta}{2 \delta}+\frac{\sqrt{(M+2 k)\left(\left(M^{2}+\delta^{2}\right)(M+2 k)+2 M^{2} \delta\right)}}{2 \delta(M+2 k)}
\end{aligned}
$$

It is straightforward to show that $\beta_{2}>1>\beta_{1}>0$. Since $P>0$ for $\beta \leq \beta_{1}$ or $\beta \geq \beta_{2}$, and we have that $0<\beta<1$, it follows that $P>0$ for $\beta \leq \beta_{1}$. Defining $\beta^{S} \equiv \beta_{1}$ completes the proof.

Proof of Lemma 4 From the reaction function equation (9), the equilibrium value of $e^{M *}$ is obtained by setting $e^{M}=\frac{\beta\left(2-e^{H M}(2-\beta)\right)}{2 k}$, and solving for $e^{M}$. Substituting (10) into (7) and (8) gives (11) and (12).

Proof of Proposition 1 Comparing (4) and (10) reveals that $e^{S *} \geq e^{M *}$ if and only if $\delta \geq \frac{\beta^{2} M^{2}}{(1-\beta)\left(2 k-\beta^{2} M\right)}$. Since we have $\delta \leq M$, we need to identify the conditions under which $\frac{\beta^{2} M^{2}}{(1-\beta)\left(2 k-\beta^{2} M\right)} \leq M$. It is straightforward to show that $\frac{\beta^{2} M^{2}}{(1-\beta)\left(2 k-\beta^{2} M\right)} \leq M$ if and only if $\frac{\beta^{2}(2-\beta) M}{2(1-\beta)} \leq k$, implying that under this condition we have $e^{S *} \geq e^{M *}$ for all $\delta \geq \frac{\beta^{2} M^{2}}{(1-\beta)\left(2 k-\beta^{2} M\right)}$. 
If $\frac{\beta^{2}(2-\beta) M}{2(1-\beta)}>k$, we have that $\frac{\beta^{2} M^{2}}{(1-\beta)\left(2 k-\beta^{2} M\right)}>M$, implying that there are no values of $\delta$ such that $\delta \leq M$ and $e^{S *} \geq e^{M *}$. In other words, if $\frac{\beta^{2}(2-\beta) M}{2(1-\beta)}>k$, it always holds that $e^{S *}<e^{M *}$. To complete the proof, define $\bar{M} \equiv \frac{2(1-\beta) k}{\beta^{2}(2-\beta)}$ and $\bar{\delta} \equiv \frac{\beta^{2} M^{2}}{(1-\beta)\left(2 k-\beta^{2} M\right)}$, and note that $\frac{\overline{\partial M}}{\partial \beta}=-\frac{2\left(2 \beta^{2}-5 \beta+4\right) k}{\beta^{3}(2-\beta)^{2}}<0$ given that $\left(2 \beta^{2}-5 \beta+4\right)>0$ for $0<\beta<1$.

Proof of Proposition 2 From the proof of Lemma 3 we have $\frac{\partial \pi_{F_{i}}^{S *}}{\partial \delta}<0$ for $\beta>\beta^{S}$. Since it always holds that $\pi_{F_{i}}^{S *}(\delta=0)<\frac{1}{2} \pi_{F_{i}}^{M *}$, it follows that for $\beta>\beta^{S}, \pi_{F_{i}}^{S *}<\frac{1}{2} \pi_{F_{i}}^{M *}$, implying that the firms obtain greater expected profits under the merger, giving (ii).

If, on the other hand, $\beta \leq \beta^{S}$, we have that $\frac{\partial \pi_{F_{i}}^{S *}}{\partial \delta} \geq 0$. Evaluating $\pi_{F_{i}}^{S *}$ at $\delta=M$ yields

$$
\pi_{F_{i}}^{S *}(\delta=M)=\frac{k \beta(1-\beta)^{2}(2-\beta) M^{2}}{(k+\beta(2-\beta) M)^{2}} .
$$

It follows that $\pi_{F_{i}}^{S *}(\delta=M) \geq \frac{1}{2} \pi_{F}^{M *}$ if and only if

$$
\frac{k(1-\beta)(2-\beta)}{(k+\beta(2-\beta) M)^{2}} \geq \frac{2(2 k+\beta M)}{(2 k+\beta(2-\beta) M)^{2}} .
$$

Since we have $M<k$, it follows that

$$
\frac{2(2 k+\beta k)}{(2 k+\beta(2-\beta) M)^{2}}>\frac{2(2 k+\beta M)}{(2 k+\beta(2-\beta) M)^{2}} .
$$

It is straightforward to show that

$$
\frac{k(1-\beta)(2-\beta)}{(k+\beta(2-\beta) M)^{2}} \geq \frac{2(2 k+\beta k)}{(2 k+\beta(2-\beta) M)^{2}}
$$

if and only if

$$
M<\frac{(\sqrt{2(1-\beta)(2-\beta)(\beta+2)}-2 \beta(4-\beta)) k}{\beta(2-\beta)\left(2+5 \beta-\beta^{2}\right)} .
$$

Hence, we obtain

$$
\frac{k(1-\beta)(2-\beta)}{(k+\beta(2-\beta) M)^{2}} \geq \frac{2(2 k+\beta k)}{(2 k+\beta(2-\beta) M)^{2}}>\frac{2(2 k+\beta M)}{(2 k+\beta(2-\beta) M)^{2}}
$$

for $M \leq M_{C} \equiv \frac{(\sqrt{2(1-\beta)(2-\beta)(\beta+2)}-2 \beta(4-\beta)) k}{\beta(2-\beta)\left(2+5 \beta-\beta^{2}\right)}$. Since for $\beta \leq \beta_{S}$ and $M \leq M_{C}$, we have $\frac{\partial \pi_{F_{i}}^{S *}}{\partial \delta} \geq 0$ and $\pi_{F_{i}}^{S *}(\delta=M)>\frac{1}{2} \pi_{F_{i}}^{M *}$, there exists $\delta_{C}$ with $0<\delta_{C}<M$ where $\delta_{C}$ is defined from $\pi_{F_{i}}^{S *}\left(\delta_{C}\right)=$ $\frac{1}{2} \pi_{F_{i}}^{M *}$ such that for $\delta \geq \delta_{C}$, it always holds that $\pi_{F_{i}}^{S *}(\delta)>\frac{1}{2} \pi_{F_{i}}^{M *}$, giving (i). Since the numerator 
of $M_{C}$ is decreasing and the denominator is increasing in $\beta$, it follows that $\frac{\partial M_{C}}{\partial \beta}<0$. Finally, it is immediate to see from the definition of $M_{C}$ that $\frac{\partial M_{C}}{\partial k}>0$.

Proof of Proposition 3 We need to prove that if $\beta \leq \beta^{S}, M \leq M_{C}$ and $\delta \geq \delta_{C}$, there exist $I_{1}$ and $I_{2}$ such that if $I_{1}<I<I_{2}$, the stand-alone structure results in positive expected profits, that is, $\pi_{F_{i}}^{S *}-I>0$, whereas the monopoly structure results in negative expected profits, that is, $\pi_{F}^{M *}-K I<0$. Define $I_{1} \equiv \frac{\pi_{F}^{M *}}{K}$ and $I_{2} \equiv \pi_{F_{i}}^{S *}$. If there exists values of $I$ such that $\frac{\pi_{F}^{M *}}{K}<I<\pi_{F_{i}}^{S *}$ it will imply $\pi_{F_{i}}^{S *}-I>0$, and $\pi_{F}^{M *}-K I<0$. For the condition $\frac{\pi_{F}^{M *}}{K}<I<\pi_{F_{i}}^{S *}$ to hold, we need to show that there are conditions under which $\frac{\pi_{F}^{M *}}{K}<\pi_{F_{i}}^{S *}$, or equivalently $\frac{\pi_{F}^{M *}}{\pi_{F}^{M *}}<K$. From the proof of Proposition 2, we have that if $\beta \leq \beta^{S}, M \leq M_{C}$ and $\delta \geq \delta_{C}, \pi_{F}^{M *} \leq 2 \pi_{F_{i}}^{S *}$ or $\frac{\pi_{F}^{M *}}{\pi_{F}^{M *}} \leq 2$. This implies that there always exist values of $K$ such that $\frac{\pi_{F}^{M *}}{\pi_{F}^{M *}}<K<2$.

Proof of Proposition 4 Using the reaction function equation in (14), we can obtain the Nash-equilibrium level of effort $e_{1}^{S}\left(\delta_{1}, \delta_{2}\right)$ and $e_{2}^{S}\left(\delta_{1}, \delta_{2}\right)$ as

$$
\begin{aligned}
& e_{1}^{S}\left(\delta_{1}, \delta_{2}\right)=\frac{\left(\beta M+\gamma \delta_{1}\right)\left(k-\beta M-\gamma \delta_{2}\right)}{k^{2}-\left(\beta M+\gamma \delta_{1}\right)\left(\beta M+\gamma \delta_{2}\right)} \\
& e_{2}^{S}\left(\delta_{1}, \delta_{2}\right)=\frac{\left(\beta M+\gamma \delta_{2}\right)\left(k-M \beta-\gamma \delta_{1}\right)}{k^{2}-\left(\beta M+\gamma \delta_{1}\right)\left(\beta M+\gamma \delta_{2}\right)}
\end{aligned}
$$

where $\gamma \equiv \beta(1-\beta)$. Since we have $M<k$, and $\delta_{i} \leq M, M \beta+\gamma \delta_{i} \leq k$ for all $0<\beta<1$, implying that $0<e_{i}^{S}\left(\delta_{1}, \delta_{2}\right)<1, i=1,2$ holds for all parameter values. Plugging $e_{1}^{S}\left(\delta_{1}, \delta_{2}\right)$ and $e_{2}^{S}\left(\delta_{1}, \delta_{2}\right)$ into firm expected profits given in (16), we obtain

$$
\pi_{F_{i}}^{S}=\frac{k\left(\beta M+\gamma \delta_{i}\right)\left(M(1-\beta)-\gamma \delta_{i}\right)\left(k-\beta M-\gamma \delta_{j}\right)^{2}}{\left(k^{2}-\left(\beta M+\gamma \delta_{i}\right)\left(\beta M+\gamma \delta_{j}\right)\right)^{2}} .
$$

Taking the partial derivative of $\pi_{F_{i}}^{S}$ with respect to $\delta_{i}$, and solving it for $\delta_{i}$, we obtain

$$
\delta_{i}=\frac{M k^{2}(1-2 \beta)+\beta M^{2}\left(\beta M+\gamma \delta_{j}\right)}{\gamma\left(2 k^{2}-M\left(\beta M+\gamma \delta_{j}\right)\right)} .
$$

Setting $\delta_{i}=\delta_{j}=\delta$, and solving the equation for $\delta$, we obtain

$$
\begin{aligned}
& \delta_{1}=\frac{k^{2}-\beta M^{2}-k \sqrt{k^{2}-M^{2}}}{M \gamma}, \\
& \delta_{2}=\frac{k^{2}-\beta M^{2}-k \sqrt{k^{2}-M^{2}}}{M \gamma} .
\end{aligned}
$$


Since $\delta_{i}$ must satisfy $0 \leq \delta_{i} \leq M$, and $\delta_{2}>M$, it follows that $\delta_{2}$ cannot be the equilibrium choice. Since $\delta_{1}<0$ when $\beta \leq \beta_{1} \equiv \frac{M-\sqrt{\left(M^{2}-k^{2}\right)+k \sqrt{k^{2}-M^{2}}}}{M}$, and given that $\delta_{i}$ must satisfy $\delta_{i}>0$, in equilibrium the firms set $\delta_{i}^{*}=0$ for $\beta \leq \beta_{1}$. In addition, since $\delta_{1}>M \beta>\beta_{2} \equiv \frac{k^{2}-k \sqrt{k^{2}-M^{2}}}{M^{2}}$ and given that $\delta_{i}$ must satisfy $\delta_{i} \leq M$, the firms set $\delta_{i}^{*}=M$ for $\beta>\beta_{2}$. The firms set $\delta_{i}^{*}=\delta_{1}$ if $\beta_{1}<\beta \leq \beta_{2}$ given that $0 \leq \delta_{1} \leq M$ for $\beta_{1}<\beta \leq \beta_{2}$. Finally, it is straight forward to verify that $\frac{\partial \pi_{F_{i}}^{S}}{\partial \delta_{i}}<0$ for $\beta<\beta_{1}$, hence, firm $i$ 's profits are maximized at $\delta_{i}=0$, and $\frac{\partial \pi_{F_{i}}^{S}}{\partial \delta_{i}}>0$ for $\beta>\beta_{2}$, and hence, firm $i$ 's profits are maximized at $\delta_{i}=M$. Finally, $\frac{\partial^{2} \pi_{F_{i}}^{S}}{\partial \delta_{i}^{2}}<0$ at $\delta_{i}=\delta_{1}$, implying that $\delta_{1}$ maximizes $\pi_{F_{i}}^{S}$. Defining $\delta^{*} \equiv \delta_{i}^{*}, i=1,2$ and $\hat{\delta} \equiv \delta_{1}$ proves the main part of the proposition. Differentiating $\hat{\delta}$ with respect to $\beta$ yields $\frac{\partial \hat{\delta}}{\partial \beta}=\frac{-\beta^{2} M^{2}-(1-2 \beta) k\left(k-\sqrt{k^{2}-M^{2}}\right)}{\beta^{2}(1-\beta)^{2} M}$. It is immediate to see that $\frac{\partial \hat{\delta}}{\partial \beta}<0$ for $\beta<\frac{1}{2}$. For $\frac{1}{2} \leq \beta<1$, it follows that $\frac{\partial \hat{\delta}}{\partial \beta}<0$ if and only if $-\beta^{2} M^{2}+(2 \beta-1) k\left(k-\sqrt{k^{2}-M^{2}}\right)<0$.Using $k>M$, it is straightforward to show that $k\left(k-\sqrt{k^{2}-M^{2}}\right)<M^{2}$. Since $2 \beta-1<\beta^{2}$, we obtain $\beta^{2} M^{2}>(2 \beta-1) k\left(k-\sqrt{k^{2}-M^{2}}\right)$, and hence, $\frac{\partial \hat{\delta}}{\partial \beta}<0$. Differentiating $\hat{\delta}$ with respect to $M$ yields $\frac{\partial \hat{\delta}}{\partial M}=\frac{k^{3}-\left(k^{2}+\beta M^{2}\right) \sqrt{k^{2}-M^{2}}}{\beta(1-\beta) M^{2}\left(\sqrt{k^{2}-M^{2}}\right)} \cdot \frac{\partial \hat{\delta}}{\partial M}>0$ if and only if $k^{3}-\left(k^{2}+\beta M^{2}\right) \sqrt{k^{2}-M^{2}}>0$, or $\beta M^{2}<\frac{k^{3}}{\sqrt{k^{2}-M^{2}}}-k^{2}$. Since $\hat{\delta}$ is defined for $\beta<\beta_{2}$, which implies $\beta M^{2}<k^{2}-k \sqrt{k^{2}-M^{2}}$, it is straightforward to show that $k^{2}-k \sqrt{k^{2}-M^{2}}<$ $\frac{k^{3}}{\sqrt{k^{2}-M^{2}}}-k^{2}$, which, in turn, implies $\beta M^{2}<\frac{k^{3}}{\sqrt{k^{2}-M^{2}}}-k^{2}$ and hence, $\frac{\partial \hat{\delta}}{\partial M}>0$. Differentiating $\beta_{1}$

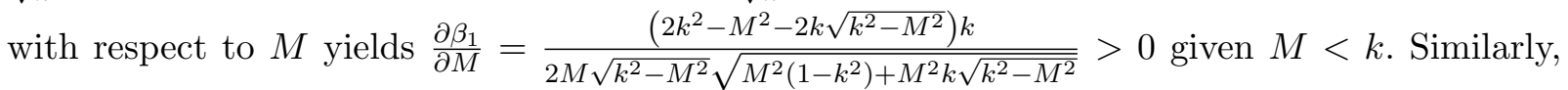
differentiating $\beta_{2}$ with respect to $M$ yields $\frac{\partial \beta_{2}}{\partial M}=\frac{\left(2 k^{2}-M^{2}-2 k \sqrt{k^{2}-M^{2}}\right) k}{M^{3} \sqrt{k^{2}-M^{2}}}>0$, given $M<k$. 